\title{
Implementasi Aplikasi Mobile Peta NKRI (Negara Kesatuan Republik Indonesia) Berbasis Android Menggunakan Metode Prototype
}

\author{
Adika May Sari ${ }^{1}$, Desri Yani ${ }^{1}$, Desy Suryani ${ }^{2}$ \\ ${ }^{1}$ Teknologi Informasi, Sistem Informasi, Universitas Bina Sarana Informatika, DKI Jakarta, Indonesia \\ ${ }^{2}$ Komunikasi Dan Bahasa, Penyiaran, Universitas Bina Sarana Informatika, DKI Jakarta, Indonesia \\ Email: 1adika.dik@bsi.ac.id, ${ }^{2}$ desriyani.dsr@bsi.ac.id, ${ }^{3}$ dessy.dsn@bsi.ac.id
}

\begin{abstract}
Abstrak-Teknologi Android berkembang dengan sangat pesat, terbukti bahwa segala sesuatu dapat dilakukan dengan mudah. Indonesia adalah negara kepulauan terbesar di dunia. Nama Alternatif negara Indonesia disebut Nusantara. Dengan Banyak nya pulau yang dimiliki, Indonesia memiliki 34 provinsi . oleh Karena itu penulis membuat program aplikasi berbasis android tentang peta Negara Indonesia. Dimana metode yang digunakan adalah metode prototype. Dengan bahasa program Android studio. Aplikasi mobile ini memudahkan user untuk melihat peta kepulauan Negara Indonesia yang terdiri dari 34 provinsi. Aplikasi ini ditujukan untuk siswa sekolah, tetapi orang awam juga bisa menggunakan nya. Dahulu kita hanya bisa melihat peta kepulauan dan provinsi dengan menggunakan buku. Dengan adanya perkembangan aplikasi mobile, maka dibuatlah aplikasi peta NKRI berbasis android. Pada aplikasi ini user bisa melihat peta Indonesia, dan bisa menggunakan fitur lain nya seperti games interaktif, pertanyaan seputar peta Indonesia untuk menambah wawasan tentang Indonesia.
\end{abstract}

Kata Kunci: Mobile; Android; Peta; Indonesia; Negara

\begin{abstract}
Android technology is developing very rapidly, it is proven that everything can be done easily. Indonesia is the largest archipelagic country in the world. The alternative name for Indonesia is called Nusantara. With its many islands, Indonesia has 34 provinces. Therefore, the author makes an android-based application program about the map of the State of Indonesia. Where the method used is the prototype method. With Android studio programming language. This mobile application makes it easy for users to view a map of the Indonesian archipelago which consists of 34 provinces. This application is intended for school students, but ordinary people can also use it. In the past we could only see maps of the islands and provinces using books. With the development of mobile applications, an Android-based application for the NKRI map was made. In this application, users can view a map of Indonesia, and can use other features such as interactive games, questions about the map of Indonesia to add insight into the map of Indonesia.
\end{abstract}

Keywords: Mobile; Android; Map; Indonesia; Country

\section{PENDAHULUAN}

Indonesia adalah sebuah Negara kepulauan. Indonesia memiliki 34 provinsi berikut ibukotanya dan memiliki keberagaman budaya dari masing-masing daerah provinsi tersebut. Menurut [1] Peta memuat lokasi di permukaan bumi, baik yang berada di daratan maupun di lautan. Pengetahuan peta sangatlah penting agar seseorang tidak tersesat dalam mencari suatu lokasi. Dari pengetahuan peta juga dapat diketahui daratan tinggi, daratan rendah, letak perkebunan, jalan darat, dan daerah pegunungan. Dengan demikian ketika seseorang memahami peta dan membawanya pada saat bepergian terutama saat menempuh perjalanan jauh, akan sangat membantu. Menurut [2] teknologi informasi mengubah gaya hidup masyarakat Indonesia menuju masyarakat modern.

Dengan adanya aplikasi mobile berbasis android ini, penulis akan melakukan sebuah pembuatan aplikasi Peta Negara Kesatuan Republik Indonesia. Dimana Aplikasi ini berisi tentang peta Indonesia yang ditujukan untuk siswa tetapi orang awam juga bisa menggunakan aplikasi ini karena di dalam aplikasi ini berisi tentang informasi kepulauan dan provinsi - provinsi, di dalam aplikasi ini juga terdiri dari soal pembelajaran tentang peta Indonesia, games edukatif yang dapat menambah wawasan bagi user yang menggunakan nya. Dimana dalam aplikasi ini user (pengguna) akan lebih mengetahui tentang daerah-daerah yang ada di Republik Indonesia ini. User tidak harus lagi membeli buku yang biasa disebut dengan Atlas. Pembuatan aplikasi ini menggunakan metode prototype dimana dengan metode ini diharapkan dapat menimimalkan kesalahan pada saat menggambarkan versi awal system. Dengan berkembangnya teknologi informatika dan telekomunikasi, android yang merupakan salah satu operating system pada suatu device smartphone sudah sangat memasyarakat dipakai semua orang dari berbagai macam golongan [3]. prototype. Pemanfaatan Sistem Informasi Geografis ini sangat berguna pada era globalisasi dan kemajuan teknologi yang sangat pesat. Informasi Geografis dapat disampaikan dengan tepat sasaran dan mudah [4].

Penelitian sebelumnya adalah Aplikasi Peta Digital Universitas Muhammadiyah Surakarta oleh Syams Kurniawan Hidayat, penelitian menjabarkan aplikasi peta digital dengan mempunyai kelebihan bisa diakses melalui Local Area Network (LAN) dan internet sehingga bisa memudahkan pencarian lokasi bagi pengguna baik dari kalangan internal maupun eksternal UMS [5]. Penelitan yang berjudul Manajemen Web Untuk Mendukung Aplikasi Informasi Peta Digital Pada Smartphone Berbasis Android. Dalam aplikasi ini data lokasi seperti data masjid, gereja, market, hotel, restoran dan rumah sakit disimpan pada web server yang memungkinkan untuk pengguna menambahkan data baru pada aplikasi dengan verifikasi yang dilakukan oleh administrator [6].

\section{METODOLOGI PENELITIAN}


Berikut adalah kerangka berfikir untuk tahapan penelitian pada perancangan sistem informasi jemput donasi berbasis android pada penetian kali ini ada beberapa tahapan yang dilakukan dapat dilihat pada gambar 1.

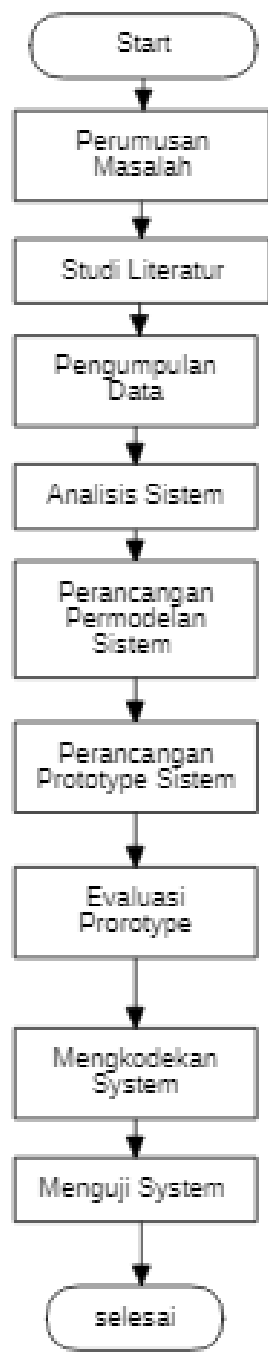

Gambar 1. Tahapan penelitian

Dimana secara keseluruhan tahapan yang dilakukan antra lain:

1 Perumusan Masalah

Tujuan Perumusan masalah adalah untuk mengidentifikasi dan mempelajari aplikasi yang berjalan sebelumnya, dan unutk menemukan solusi sistem aplikasi yang sedang berjalan.

2 Studi Literatur

Pada tahap ini penulis mencari sumber referensi yang berhubungan dengan topik yang dibahas dalam penelitian, sehingga hasil penelitian sesuai dengan kaidah-kaidah dalam penelitian.

3 Pengumpulan Data

Pengumpulan data diperoleh dari riset yang dilakukan oleh penulis, diantaranya adalah melalui riset terhadap aplikasi mengenai peta Negara Indonesia yang telah ada sebelumnya kemudian aplikasi ini dikembangkan agar menjadi lebih baik lagi.

4 Analisis Sistem

Penulis melakukan analisis terhadap aplikasi yang sedang berjalan, permasalahan-permasalahan pokok yang dihadapi dari aplikasi sebelumnya, mencari data tentang kebutuhan aplikasi agar mendapatkan solusi yang terbaik untuk memecahkan permasalahan tentang pembuatan peta Negara Indonesia ini. Serta penerapan metode Prototype untuk sistem usulan yang menjadi solusi dari penulis.

5 Perancangan Permodelan Sistem

Penulis merancang sistem dengan menggunakan usecase Diagram untuk mendefinisikan sistem yang sedang berjalan dan sistem yang diusulkan oleh penulis.

6 Perancangan Prototype Sistem

Membangun prototyping dengan membuat perancangan sementara yang berfokus pada penyajian kepada user. Pada tahap ini penulis merancang prototype Aplikasi mobile Peta Negara Indonesia berbasis android dengan 1 user yang terlibat yaitu pengguna yang menginstal aplikasi ini di android.

7 Evaluasi Prorotype

Evaluasi ini dilakukan oleh user apakah prototype yang sudah dibangun sudah sesuai dengan keinginan user.

8 Mengkodekan System

Dalam tahap ini prototyping yang sudah disepakati diterjemahkan ke dalam bahasa pemrograman yang sesuai. 
Journal of Information System Research (JOSH)

Volume 2, No. 4, Juli 2021

ISSN 2686-228X (media online)

Hal: 288-292

9 Menguji System

Pada tahap pengujian system, koding yang telah dibuat sebelumnya akan diuji apakah dapat berjalan dengan baik

\subsection{Aplikasi Mobile}

Aplikasi mobile berasal dari dua kata, yaitu aplikasi dan mobile. Secara istilah, aplikasi adalah program siap pakai yang dibuat untuk melaksanakan suatu fungsi untuk pengguna atau aplikasi yang lain sedangkan mobile adalah perpindahan dari suatu tempat ke tempat yang lain. Secara lebih lengkap, aplikasi mobile adalah program siap pakai yang melaksanakan fungsi tertentu yang dipasang pada perangkat mobile[7].

\subsection{Android}

Android merupakan suatu software (perangkat lunak) yang digunakan pada mobile device (perangkat berjalan) yang meliputi sistem operasi, middleware, dan aplikasi inti. Android Standart Development Kit (SDK) menyediakan alat dan Application Programming Interface (API) yang diperlukan untuk memulai pengembangan aplikasi pada platform Android menggunakan bahasa pemrograman Java, yaitu kode Java yang terkompilasi dengan data dan file resources yang dibutuhkan aplikasi dan digabungkan oleh app tools menjadi paket Android [8]. Dalam pembuatan aplikasi mobile NKRI berbasis android penulis menggunakan metode prototype. Metode prototype adalah metode pengembangan yang sangat cepat dan pengujian model kerja aplikasi baru melalui proses interaksi yang berulang-ulang sehingga dapat digunakan dengan baik. Tujuan metode prototype adalah mengembangkan model menjadi sistem final. Sehingga sistem ini akan dikembangkan dengan cepat dan biayanya menjadi lebih rendah.

\subsection{Model Prototype}

Prototipe adalah salah satu pendekatan dalam rekayasa perangkat lunak yang secara langsung mendemonstrasikan bagaimana sebuah perangkat lunak atau komponenkomponen perangkat lunak akan bekerja dalam lingkungannya sebelum tahapan konstruksi aktual dilakukan [9].

Model prototipe digunakan sebagai indikator dari gambaran yang akan dibuat pada masa yang akan datang dan membedakan dua fungsi eksplorasi dan demonstrasi.

Model Prototipe Beberapa mode prototipe :

1) Reusable prototype : prototipe yang akan ditransformasikan menjadi produk final.

2) Throwaway prototype : prototipe yang akan dibuang begitu selesai menjalankan maksudnya.

3) Input/output Prototype : prototipe yang terbatas pada antar muka pengguna (user interface).

4) Processing Prototype : prototipe yang meliputi perawatan file dasar dan proses-proses transaksi.

5) System Prototype : prototipe yang merupakan model lengkap dari perangkat lunak

Proses Prototipe pada model prototipe adalah :

1) Pengumpulan kebutuhan.

Developer dan klien bertemu dan menentukan tujuan umum, kebutuhan yang diketahui dan gambaran bagian-bagian yang akan dibutuhkan berikutnya.

2) Perancangan

Perancangan dilakukan cepat dan rancangan memiliki semua aspek software yang diketahui, dan rancangan ini menjadi dasar pembuatan prototipe.

3) Evaluasi prototipe

Klien mengevaluasi prototipe yang dibuat dan digunakan, memperjelas kebutuhan sistem

\section{HASIL DAN PEMBAHASAN}

\subsection{Rancangan Use Case Diagram}

Hubungan antar user dengan system aplikasi android digambarkan dengan use case diagram dibawah ini, dimana user mulai menjalankan aplikasi dengan mengklik aplikasi yang sudah di install di dalam perangkat mobile.

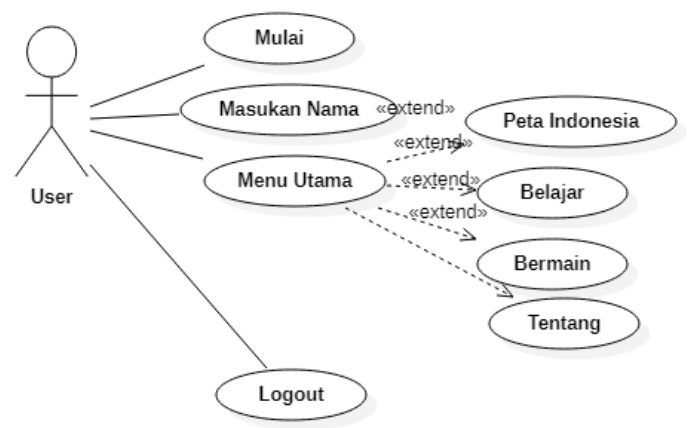

Gambar 2. Use case Diagram Aplikasi Mobile Peta

\subsection{Activity Diagram}

Rancangan aktivitas atau aliran kerja dalam program aplikasi mobile ini dilakukan oleh user dan sistem. Dibawah ini adalah activity diagram aplikasi mobile peta NKRI. 


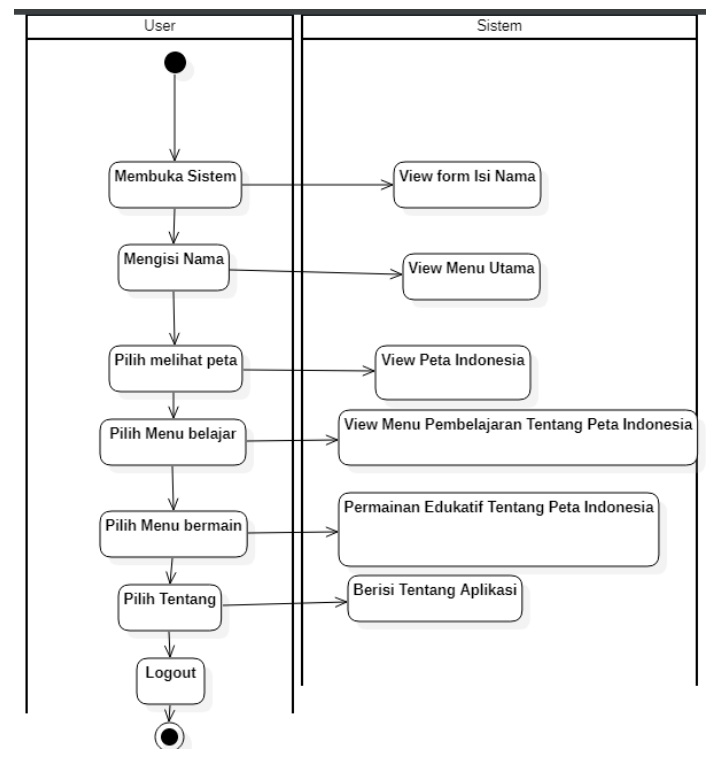

Gambar 3. Activity Diagram Aplikasi Mobile Peta

\subsection{Implementasi Program}

Berikut merupakan tampilan aplikasi
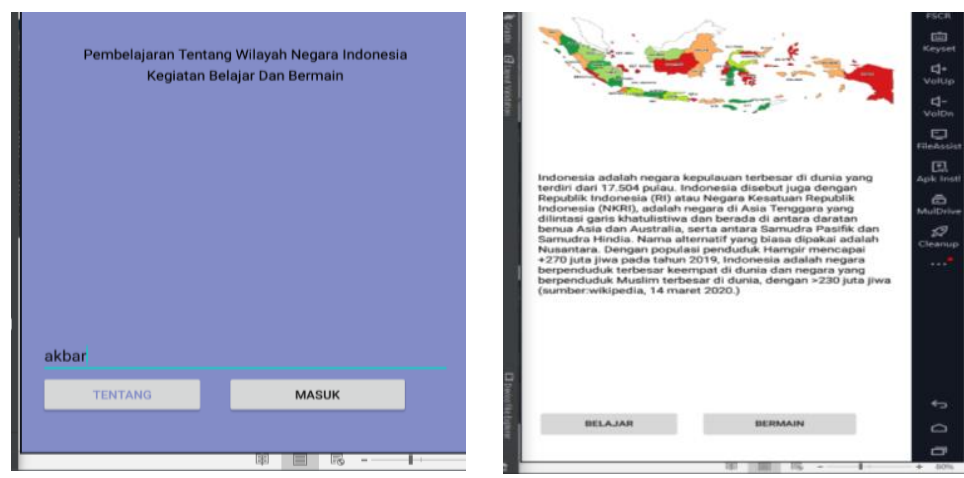

Gambar 4. Tampilan awal dan menu belajar serta permainan

\subsection{Pengujian Aplikasi}

Pengujian aplikasi mobile peta Negara Indonesia ini menggunakan pengujian blackbox testing. Hasil pengujian menunjukan bahwa aplikasi mobile ini berhasil 100\%. Berikut scenario pengujian blackbox testing.

Tabel 1. Hasil Pengujian

\begin{tabular}{lllc}
\hline No & Pengujian & \multicolumn{1}{c}{ Prosedur pengujian } & Hasil \\
\hline 1 & Login & Masukan nama user & valid \\
2 & Belajar & Klik menu belajar di menu utama & valid \\
3 & Bermain & Klik menu belajar di menu utama & valid \\
4 & tentang & Klik tentang di halaman utama saat menuliskan nama & valid \\
5 & logout & Klik logout di halaman utama & valid \\
\hline
\end{tabular}

\section{KESIMPULAN}

Adanya aplikasi Peta ini dapat memudahkan seseorang yang ingin belajar mengetahui tentang betapa indah dan kaya nya negara ini. Dapat menambah pengetahuan dan wawasan bagi user yang mendownload dan menggunakan aplikasi ini.Aplikasi ini berjalan di system operasi android. Aplikasi ini di buat dengan bahasa pemrograman android studio dan menggunakan emulator pada saat dijalankan di laptop. Selanjutnya diharapkan system ini dapat dikembangkan dalam beberapa hal, seperti menu yang ada di dalam aplikasi, bisa ditambahkan kebudayaan dan navigasi pada saat kita akan mencari suatu daerah dalam peta tersebut.

\section{REFERENCES}

[1] N. Sutarna, "PENERAPAN METODE PENUGASAN UNTUK MENINGKATKAN KEMAMPUAN MEMAHAMI PETA PADA SISWA SEKOLAH DASAR,” vol. 16, no. April, pp. 34-43, 2016.

[2] M. Akif, Y. A. Prasetyo, N. Ambarsari, J. Telekomunikasi, and T. Buah, "PENGEMBANGAN APLIKASI E-CRM BOJANA," vol. 2, no. 1, pp. 1057-1070, 2015. 


\section{Journal of Information System Research (JOSH)}

Volume 2, No. 4, Juli 2021

ISSN 2686-228X (media online)

Hal: $288-292$

[3] T. A. Utomo, B. D. Yuwono, and F. J. Amarrohman, "Jurnal Geodesi Undip,” vol. 6, no. April, pp. 1-11, 2017.

[4] A. Rachmawati, A. L. Nugraha, and M. Awaluddin, "JALUR BATIK SOLO TRANS BERBASIS ANDROID," vol. 6, no. April, pp. 46-55, 2017.

[5] S. K. Hidayat, “APLIKASI PETA DIGITAL,” vol. II, pp. 56-60, 2019.

[6] E. S. Nugroho, "MANAJEMEN WEB UNTUK MENDUKUNG APLIKASI INFORMASI PETA DIGITAL PADA SMARTPHONE BERBASIS ANDROID," 2018.

[7] M. Siregar and I. Permana, "RANCANG BANGUN APLIKASI BERBASIS MOBILE UNTUK NAVIGASI KE ALAMAT PELANGGAN TV BERBAYAR ( Studi Kasus : Indovision Cabang Pekanbaru ),” vol. 2, no. 1, pp. 82-94, 2016.

[8] M. Siddik and A. Nasution, "PERANCANGAN APLIKASI PUSH NOTIFICATION," vol. IV, no. 2, 2018.

[9] E. Yanuarti, "Prototipe Sistem Informasi Seleksi Penerimaan Pegawai Tugas Belajar,” vol. 3, no. 2, pp. 36-41, 2017. 